\title{
Bickmann, C., Immanuel Kants Weltphilosophie
}

\section{Emiliano Acosta}

\section{(2) OpenEdition}

\section{Journals}

\section{Edición electrónica}

URL: http://journals.openedition.org/ref/569

DOI: $10.4000 /$ ref.569

ISSN: 2258-014X

\section{Editor}

EuroPhilosophie Editions

Referencia electrónica

Emiliano Acosta, «Bickmann, C., Immanuel Kants Weltphilosophie », Revista de Estud(i)os sobre Fichte [En línea], 9 | 2014, Publicado el 28 diciembre 2014, consultado el 25 septiembre 2020. URL : http:// journals.openedition.org/ref/569; DOI : https://doi.org/10.4000/ref.569

Este documento fue generado automáticamente el 25 septiembre 2020

(c) EuroPhilosophie 


\title{
Bickmann, C., Immanuel Kants Weltphilosophie
}

\author{
Emiliano Acosta
}

\section{REFERENCIA}

Bickmann, C., Immanuel Kants Weltphilosophie, Serie: Interkulturelle Bibliothek Nordhausen: Traugott Bautz, 2006, 159 pp., ISBN 9783883093031

1 Claudia Bickmann, en la actualidad una de las más interesantes comentadoras alemanas de la filosofía kantiana, dirige hace ya varios años un grupo de investigación sobre filosofía intercultural en la Universidad de Colonia. Lo que caracteriza a este grupo es la perspectiva desde la cual estudia y discute la problemática actual acerca del diálogo entre culturas y religiones: la filosofía trascendental kantiana, el idealismo alemán y las filosofías de Husserl, Heidegger y Levinas. La elección de estos autores puede llevar a suponer cierto eurocentrismo en la perspectiva escogida por este grupo. Sin embargo, se trata, según cree el reseñador, de un gesto de honestidad intelectual: en tiempos de interculturalidad ya no hay lugar para discursos universalistas ni en lo que respecta a la forma ni en lo que respecta al contenido del discurso. Por esta razón, cada discurso debe comenzar por hacer explícitos sus presupuestos, su proveniencia y sus condicionamientos históricos. Aceptada la imposibilidad de una perspectiva superadora de la historicidad del pensar, cada discurso debe ser consciente que lo intercultural e interreligioso es inevitablemente tratado desde una perspectiva particular. $\mathrm{Y}$ esto es precisamente lo que este grupo propone: discutir un problema que atañe a la comunidad global, pero dentro de los límites históricos impuestos al pensamiento, en este caso, europeo. En palabras de su directora este grupo busca principalmente una actualización del legado de estos filósofos mediante la demostración del potencial de los mismos para analizar críticamente y enriquecer los debates actuales sobre interculturalidad e interreligiosidad. Su libro Immanuel Kants Weltphilosophie ilustra de 
manera clara este proyecto y bien puede ser visto como una primera concreción del mismo.

La tesis principal de este libro es que la filosofía kantiana posee un concepto de filosofía universal (Weltphilosophie) y, por ende, una concepción de mundo en cuanto idea unificadora y totalizadora de la realidad en sentido amplio. En efecto, en este libro C. B. se propone mostrar que la filosofía kantiana logra "salvar" el concepto de mundo, en cuanto "ordo" de todos los ámbitos del ser, puesto en cuestión por la modernidad (europea). Junto con el concepto de "mundo" la filosofía kantiana, según C. B., ofrece al individuo una explicación sistemática de la totalidad de la realidad y del "proceso de devenir un ser humano" (10) que pone límites a todo reduccionismo cientificista o naturalista en general. Dicho en términos heideggerianos, la filosofía universal de Kant provee al individuo de un mundo en el que aún es posible habitar de un modo humano.

El punto de partida de Immanuel Kants Weltphilosophie es el libro de R. Brague Die Weisheit der Welt (München: Beck, 2006). Allí Brague sostiene que la concepción unificadora del mundo, que tanto el mundo griego como las religiones monoteístas supieron crear y conservar, se perdió con la llegada de la modernidad, entendida en sentido amplio, es decir, desde Descartes hasta nuestros días. Según C. B. este tipo de interpretaciones que contraponen la modernidad a las filosofías que la precedieron y culpan sin más a la primera de la deshumanización y desintegración del mundo en cuanto totalidad, desconocen que el pensamiento kantiano posee una filosofía del mundo o concepción del ser en sentido totalizador (Weltphilosophie). La filosofía kantiana, sostiene la autora, "encierra un potencial inagotable en lo que respecta a las cuestiones actuales urgentes acerca de la relación entre moral, política y religión y entre conocimiento de mundo y de sí en sentido práctico y teórico." (ibíd..)

4 La reconstrucción del concepto kantiano de mundo en cuanto "ordo" que ofrece la autora se articula en tres partes precedidas de una extensa introducción (pp. 9-50) en la que C.B., por un lado, resume la posición contra la cual va dirigido este libro y describe en líneas generales su modo de leer a Kant y la tesis a demostrar, a saber: que la concepción totalizadora/unificadora del mundo kantiana ha de verse en el modo en que Kant logra reunir y articular los usos teórico y práctico de la razón sin tener que postular por esto la disolución de una de las esferas del ser en la otra. (41) Por otro lado, C. B. ofrece en la introducción un muy breve esbozo de una historia de las concepciones de mundo y sus distintas crisis en la filosofía occidental, de Platón al existencialismo, pasando por el neoplatonismo y su recepción en el mundo cristiano e islámico, la Biblia, el racionalismo moderno, Kant, el idealismo alemán y la fenomenología husserliana. A pesar de la brevedad de este análisis histórico-filosófico C. B. logra hacer visible la dinámica de este proceso de desintegración del mundo en el pensamiento y/o la filosofía occidental así como también el rol central de la figura de Kant en el mismo. En efecto, el filósofo de Königsberg, tal como muestra C. B., ha servido tanto a filosofías que buscaron recuperar la unidad del concepto de mundo como a posiciones antimetafísicas del pensamiento occidental. (21)

5 La primera parte, intitulada "Autoconocimiento como primer paso en el camino a una filosofía universal posible" (pp. 51-94) ilustra uno de los pilares de la filosofía intercultural e interreligiosa que, siguiendo el espíritu kantiano, propone Bickmann: cada posición debe primero conocerse, conocer sus límites y posibilidades, para luego poder articular un discurso con sentido. 
6 Uno de los aportes más interesantes de esta primera parte, no sólo para el debate en cuestión, sino además para un mayor conocimiento del espíritu de la filosofía kantiana, es, según el reseñador, la reconstrucción de la idea kantiana de metafísica a partir de la identificación, que Kant sugiere en su Opus postumum, entre doctrina de la sabiduría (Weisheitslehre), filosofía (Philosophie) y sabiduría universal o conocimiento de mundo (Weltweisheit). De este modo los pasajes conocidos de Kant acerca de los límites y el destino trágico de la metafísica se muestran en una tensión tan interesante como productiva a la luz de los fines últimos que Kant impone al pensar. La metafísica, entonces, ya no aparece solamente como una ciencia en decadencia o absurda, sino antes bien como la "consumación de toda cultura de la razón humana". (53) De este modo Bickmann arroja luz sobre el espíritu o idea central del proyecto crítico kantiano, a saber, que el mismo no está movido por un mero interés científico, sino por un interés moral y existencial principalmente ligado a la pregunta acerca de la destinación (Bestimmung) del ser racional finito. Este aspecto de la filosofía kantiana es uno de los motivos que, asombrosamente, menos llama la atención de la literatura actual más especializada sobre Kant, a pesar de que sea Kant mismo, por cierto, quien lo declare sin ambages en el prefacio a la segunda edición de su $\mathrm{KrV}$ al referirse al sentido positivo de su crítica de la metafísica. ( $\mathrm{KrV}$ B XXV y ss.)

7 La segunda parte de la investigación de C. B. (pp. 95-118), "La idea de un orden universal entre individuo y todo determinado continuamente", se concentra, como se anuncia en el título, en la tensión que se da en la idea de un orden universal (Weltordnung) entre individuo y totalidad. C. B. ofrece en esta sección de su libro una lectura detenida del tercer capítulo de la dialéctica trascendental de la KrV: sobre el ideal de la razón pura. C. B. intenta mostrar aquí que la relación entre lo individual determinado y la totalidad determinable presente en la definición y en el conocimiento del objeto en su concreción individual es aplicable tanto a la filosofía kantiana teórica como práctica. La idea kantiana de "omnitudo realitatis" es expuesta, entonces, como la fuente última de sentido teórico y práctico de cada determinación particular.

8 Al final de esta segunda parte (apartado 4) C. B. ensaya una aproximación al problema de la intersubjetividad a partir del aparato conceptual que Kant brinda en su análisis del ideal de la razón pura. El otro en su otredad es, siguiendo a C. B., elemento constitutivo del conocimiento de sí, así como la totalidad determinable lo es del caso particular. C. B. entiende la intersubjetividad como exigencia, dirigida a cada individuo, de traducir su lenguaje particular para volver público/comunicable aquello que en principio sólo concierne al ámbito de lo privado del sujeto. Este análisis de la intersubjetividad lleva a C. B. a plantear el desafío de la así llamada filosofía continental frente al discurso de las neurociencias y de la neurofilosofía. Según C. B. la teoría fichteana de la constitución pre-consciente de la estructura cognitiva (115) así como también los aportes de la fenomenología de Husserl ofrecen herramientas conceptuales con gran potencial para hacer frente al intento hegemónico de las "neuro"-disciplinas en aquellos debates que hasta ahora eran campo exclusivo de las ciencias humanas. (116-118)

9 "El pensamiento supremo de la filosofía kantiana" al que refiere el título de la tercera y última parte de este libro (pp. 119-148) es, según la autora, la idea de la realización armónica de todas las potencialidades de la razón humana. Esta realización conduce ciertamente a la idea de un ser perfecto, Dios, pero también a la idea de que la misma debe tener concreción en el mundo. Los fines últimos que Kant impone a la razón 
humana aparecen entonces como predicados de un ser (si bien sin existencia objetiva) y como elementos esenciales del proyecto emancipador de la humanidad como hilo conductor de la historia. Según C. B. la verdadera consumación del giro copernicano kantiano consiste en que Kant quería demostrar no solo que un mundo regido por leyes morales es posible, sino que además debe llegar a ser efectivamente real. (120)

En esta tercera parte C. B. analiza la segunda parte de la $K U$. Además de exponer en qué medida la tercera crítica puede ser entendida como el lugar en que se da la mediación entre los usos teórico y práctico de la razón, C. B. brinda especial atención al elemento teleológico en el pensamiento kantiano. Según la autora la teleología no se limita a la tercera Crítica, sino que está presente en todo el proyecto crítico kantiano: "el principio guía de las tres críticas kantianas es la noción de fin". (119)

11 Pensado en términos teleológicos el proyecto crítico kantiano adquiere una dinámica renovada a la luz de las lecturas parciales contemporáneas de la obra de Kant. En esta dinámica la armonía entre orden natural y orden moral se muestra en el perspectivismo (teórico, moral, estético) que Kant ideó para lograr reunir esta diversidad de visiones en la idea de mundo en cuanto "ordo". Esta diversidad de visiones es aquello que Kant pensó como el objeto de la filosofía universal o, dicho con palabras del Kant del Opus postumum, de la filosofía en sentido cosmopolita ("sensu cosmopolitico"). (145)

Si bien el libro presenta serios errores de edición ("Braque" en lugar de "Brague", "II" en lugar de "III" para la tercera parte, falta de uniformidad en el formato de los subtítulos), el reseñador quiere resaltar que el formato en general ha sido bien diseñado para lo que debiera entenderse como un libro introductorio. Merece ser mencionado el hecho de que la autora ofrece al final del libro una síntesis argumentativa del libro, lo cual ciertamente ayuda a obtener una primera visión global de la tesis de C. B.. (153-157)

El reseñador sugiere complementar el análisis de C. B. de los escritos póstumos kantianos con otros pasajes del Opus postumum, no tratados por C. B., en los que Kant se ocupa del juicio disyuntivo de Spinoza "Deus sive natura", el cual para Kant ilustra de modo no trascendental el ideal de la razón pura. En lo que refiere a la idea de mundo y su desintegración en la modernidad, el reseñador cree que el aporte de C. B. es valioso para distinguir matices esenciales entre las figuras más importantes de la modernidad y así deconstruir la visión simplificadora y reduccionista de la misma.

14 Así mismo entiende que la recuperación de la visión kantiana de la idea de mundo en nuestro presente no sólo debe ser contrapuesta a estudios anti-modernos como los de Brague, sino además puesta en diálogo, por un lado, con los últimos grandes aportes de la filosofía continental europea sobre este tema, como la reflexión de Jean-Luc Nancy sobre la Creación del mundo o la mundialización; y, por otro, con discursos periféricos provenientes no de Oriente sino del más allá del Occidente, como las posiciones de W. Mignolo y E. Dussel, entre otros.

15 Más allá de estas observaciones, cada línea de este libro muestra las excelentes cualidades de C. B. como especialista en Kant y filósofa de la interculturalidad y de la interreligiosidad. En este sentido este libro es una recomendable fuente de consulta no sólo para quien desee conocer en detalle qué es filosofía sensu stricto (filosofía como 
doctrina de la sabiduría) para Kant, sino además para aquel que quiera iniciarse en el campo de la filosofía intercultural. 